\title{
Quantification of Strawberry Plant Growth and Amount of Light Received Using a Depth Sensor
}

\author{
Masaaki TAKAHASHI ${ }^{1}$, Shiori TAKAYAMA ${ }^{1}$, Hiroki UMEdA ${ }^{2}$, Chie YoshidA $^{1 *}$, \\ Osamu KoIKE ${ }^{1}$, Yasunaga IwASAKI ${ }^{3}$ and Wataru SUGENO ${ }^{4}$ \\ ${ }^{1}$ Miyagi Prefectural Institute of Agriculture and Horticulture, 1 Higashikongoji, Takadate-Kawakami, \\ Natori, Miyagi 981-1243, Japan \\ ${ }^{2}$ College of Bioresource Sciences, Nihon University, 1886 Kameino, Fujisawa, Kanagawa 252-0080, Japan \\ ${ }^{3}$ Institute of Vegetable and Floriculture Science, NARO, 3-1-1 Kannondai, Tsukuba, Ibaraki 305-8666, Japan \\ ${ }^{4}$ Agricultural Production Corporation GRA Inc, 47 Sakuratsutsumi, Yamadera,Yamamoto, Miyagi 989-2201, Japan
}

(Received June 4, 2019; Accepted November 16, 2019)

\begin{abstract}
Temperature control, fertilization management and long-day treatments are commonly implemented to achieve optimal growth control in strawberry (Fragaria $\times$ ananassa Duch.). Control of these parameters has typically relied on visual evaluation of plants by producers. For advanced production control, it is necessary to continuously monitor growth and amounts of light received. In this study, we quantified the height of strawberry plants, and leaf area receiving direct sunlight in different leaf layers over time using Kinect, a depth sensor. Data from the sensor enabled evaluation of temporal changes in plant height and of the differences in the stratification of strawberry plants grown in greenhouses at two different low nighttime temperatures. The amount of light received by different layers of the entire plant community could be estimated from sensor measurements, and was directly correlated with yield and dry weight. Our results demonstrate that a depth sensor like Kinect can quantify essential information on strawberry growth and amounts of light received. Further improving the accuracy of measurement by sensors could lead to the development of effective cultivation management methods based on the amount of photosynthesis and growth of plants.
\end{abstract}

Keywords : environmental control, growth monitoring, Kinect, leaf area, plant appearance

\section{INTRODUCTION}

In Miyagi Prefecture, Japan, the scale of strawberry cultivation facilities has recently increased and productivity has improved because of various environmental controls. For example, long-day treatment is conducted for promoting leaf growth (Vince-Prue and Guttridge, 1973). Control of atmospheric carbon dioxide, known to increase strawberry yield, is used widely in strawberry cultivation greenhouses (Lieten, 1997; Wada et al., 2010). Temperature management is also important for obtaining high yields of strawberries (Hidaka et al., 2016). On the basis of the environmental information in greenhouses, producers can continuously control the environment. Skilled producers base their cultivation management on a combination of environmental information and plant information obtained from growth surveys. Growth surveys are useful because they quantify and record the growth state of strawberries; however, as the work involved takes time, and the majority of producers judge growth state by plant appearance and they do not keep records.

The vegetative and reproductive growth of strawberries both need to be properly controlled, yet experts cur- rently carry out this task based on experience and plant growth data. In Miyagi Prefecture, the management target for strawberry is to obtain a plant height of $>25 \mathrm{~cm}$ during the winter season by temperature control, fertilizer management, carbon dioxide control and long-day treatment. While plant height is regarded as an index of management because it is easy to measure, this parameter is not sufficient to quantify strawberry vigor. Skilled producers look at the appearance of strawberry plants to assess vigor, and plant height is only an auxiliary indicator. Plant height is usually measured once a week rather than daily. The optimal method for assessing strawberry growth has not yet been determined scientifically and management methods for strawberry plants vary among producers. In addition, inexperienced producers may struggle to perform adequate controls.

There is a need for a management technique based on quantitative information. Although data on strawberry plant height is currently used, the amount of data obtained from visual inspection is limited. Therefore, it is necessary to develop a method that can easily evaluate the growth of strawberry plants at different times and can accurately quantify their appearance. A technique for acquiring plant data using a three-dimensional (3D) shape sensor has been

Corresponding author : Masaaki Takahashi, fax: +022-383-9907, e-mail: takahashi-ma306@pref.miyagi.lg.jp

*Present address: Miyagi Prefectural Agriculture Department, 3-8-1 Honchou, Aoba-ku, Sendai, Miyagi 980-8570, Japan 
developed recently (Kaize et al., 2012). Multiview stereovision and 3D ray-tracing have also been employed for monitoring sweet pepper (Kim et al., 2016; Zhang et al., 2016). If these technologies were to be introduced in horticultural facilities, routine monitoring of plant growth could be facilitated and the data numerically recorded. The implementation of such methods would make it possible to improve production efficiency as the data obtained would accumulate and could be shared among producers. However, these techniques must be cost effective to be widely implemented.

Kinect (Kinect for Windows v1; Microsoft Corporation, Redmond, Washington, USA) is an inexpensive and effective 3D sensing device developed by Microsoft (Paulus et al., 2014). Plant measurement using Kinect has been performed in various plant species (Azzari et al., 2013; Li et al., 2015; Jiang et al., 2016). We have previously shown that Kinect can quantify the height and structure of strawberry and tomato plants; plant heights of $10^{-}-25 \mathrm{~cm}$ in strawberry could be measured by Kinect with the same accuracy as manual measurement (Takahashi et al., 2018). In tomato, the correlation between the actual measured and predicted leaf area values was confirmed when the leaf area index (LAI) was lower than about 2 (Umeda et al., 2018). In Miyagi Prefecture, cultivation management based on plant height is conducted for maintaining plant growth vigor in the winter season. Total canopy photosynthesis can be used as baseline data for predicting crop production (Monteith, 1965). Therefore, leaf area measurements are important for estimating photosynthesis, which greatly contributes to yield. These parameters, plant height and leaf area, are therefore indispensable for managing the cultivation of strawberry plants.

In this study, we show that Kinect can detect differences in the appearance of strawberry plants in different cultivars and growth environments. Because Kinect can measure the area of leaves receiving direct sunlight in different layers, we estimated the amount of received light for a community of strawberry plants at different planting densities and examined how this influenced yield. Furthermore, we investigated the validity of the leaf area estimated by Kinect.

\section{MATERIALS AND METHODS}

Measurement of plant height and amount of light received by leaf area and by layer in different cultivars and cultivation management using Kinect (Experiment 1)

The experiment was performed at two greenhouses (greenhouse-A, greenhouse-B) in Natori, Miyagi Prefecture. The varieties used were 'Mouikko' and 'Tochiotome', each settled on September 20, 2016. Plants were cultivated on a coconut shell medium (cocoblock; Kaneko Seeds Co., Ltd., Maebashi, Japan) in a cultivation bed ( $8 \mathrm{~m}$ long $\times 30$ $\mathrm{cm}$ wide $\times 100 \mathrm{~cm}$ high) with an $18 \mathrm{~cm}$ interval between plants and $15 \mathrm{~cm}$ inter-row spacing. Plants were doublestaggered. The $\mathrm{CO}_{2}$ concentration in the greenhouses was maintained at approximately $600 \mathrm{ppm}$ throughout the day.

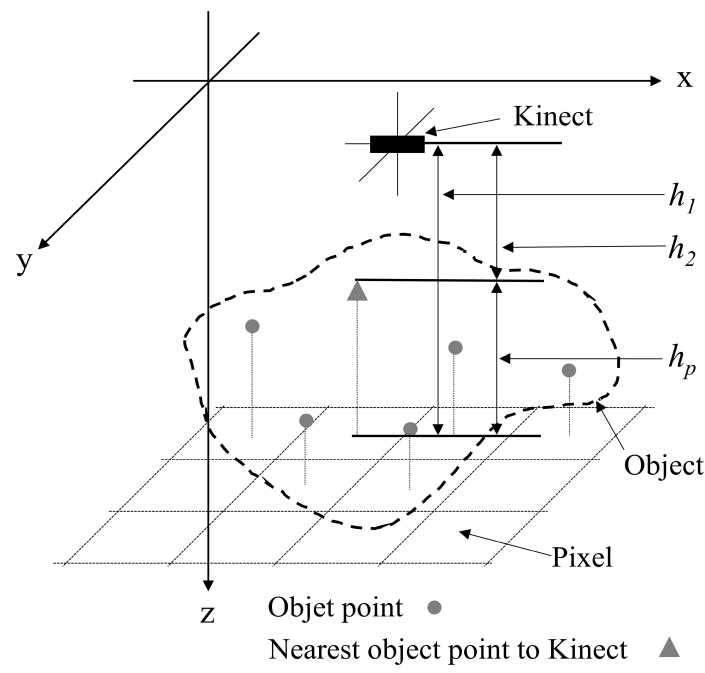

Fig. 1 Method used to measure strawberry plant height using Kinect. $h_{1}$ : distance from Kinect set-up point to the surface of cultivation bed; $h_{2}$ : distance from Kinect set-up point to the top leaf of the strawberry plant; $h_{\mathrm{p}}$ : strawberry plant height $\left(h_{1}-h_{2}\right)$.

The minimum night temperatures were $5^{\circ} \mathrm{C}$ in greenhouseA and $8^{\circ} \mathrm{C}$ in greenhouse-B. Spatial data on strawberry plants were captured using Kinect for Windows v1 (Microsoft Corp., Redmond, WA, USA) connected to a personal computer (Intel Core i5-6500, CPU 3.2GHz and 4G RAM). As Kinect was developed to control video games through gestures and spoken commands, it features a visible-light camera (resolution, $640 \times 480$ pixels at $30 \mathrm{fps}$ (flames per second)), an infrared-light camera for measuring depth $(320 \times 240$ pixels at $30 \mathrm{fps})$, an infrared projector and a microphone array. The depth sensor of the version of Kinect used in this study adopts a method called light coding, which reads the projected infrared pattern and captures depth data from the distortion of the pattern (Freedman et al., 2007; Khoshelham and Elberink, 2012). The Kinect has two depth ranges: $0.8-4 \mathrm{~m}$ in default-range mode and $0.4-3 \mathrm{~m}$ in near-range mode. The viewing angle is $43^{\circ}$ vertical by $57^{\circ}$ horizontal. For the analysis, we used software that captures visible and infrared-light image output from Kinect, enabling us to observe depth data in real time (Kurosaki et al., 2016a; 2016b). Kinect was set at a height of approximately $1.8 \mathrm{~m}$ from the cultivation bed to measure the height of six strawberry plants. Plant height $\left(h_{p}\right)$ was calculated using the following equation based on the parameters described in Fig. 1:

$$
h_{p}=h_{1}-h_{2}
$$

where $h_{l}$ is the distance from the Kinect set-up point to the surface of cultivation bed, and $h_{2}$ is the distance from the Kinect set-up point to the top leaf of the strawberry plant. To calculate the area of the crop leaves, the program counts the number of pixels corresponding to crop leaves. The area per pixel was defined as the projected area and was calculated using the distance from the Kinect and leaf surface. The projected leaf area per square meter of the strawberry plants above the cultivation bed was extracted 


\section{GROWTH MONITORING INSTRUMENT}

and taken as leaf area receiving direct sunlight. Furthermore, to evaluate strawberry plant appearance and the lightreceiving parts, the leaf area receiving direct sunlight for each $10 \mathrm{~cm}$ layer was obtained. The temperature of the greenhouse was monitored by a sensor (PetitLogger GL100; Graphtec CO., Ltd., Yokohama, Japan).

Relationship between the appearance of strawberry plants, the amount of received light using Kinect and yield at different planting densities (Experiment 2)

The experiment was conducted using a portion of the cultivation bed within a cultivation area $\left(2,400 \mathrm{~m}^{2}\right)$ in a Venlo-type steel greenhouse with a $4.5 \mathrm{~m}$ section length in Yamamoto Town, Miyagi Prefecture. On September 20, 2016, strawberry plants 'Mouikko' were cultivated on a coconut shell medium (cocoberryfarm; Kaneko Seeds Co., Ltd., Maebashi, Japan) in a cultivation bed (40 $\mathrm{m}$ long $\times 30$ $\mathrm{cm}$ wide $\times 80 \mathrm{~cm}$ high). Planting intervals were 13,18 and $23 \mathrm{~cm}$, corresponding to planting densities of 10.8, 8.0 and 5.8 plants $/ \mathrm{m}^{2}$, respectively. The $\mathrm{CO}_{2}$ concentration in the greenhouse was maintained at $600-800 \mathrm{ppm}$ throughout the day and a crown-heating system was used from the beginning of November 2016 until late February 2017. Kinect was set up at a height of approximately $2.2 \mathrm{~m}$ from the cultivation bed. The canopies of 28 plants (10.2 plants $\left./ \mathrm{m}^{2}\right), 24$ plants $\left(8.0\right.$ plants $\left./ \mathrm{m}^{2}\right)$ and 20 plants $(5.8$ plants $/ \mathrm{m}^{2}$ ) were monitored by Kinect. Kinect continuously measured plant height and leaf area receiving direct sunlight. The amount of received light for each layer was calculated by multiplying leaf area receiving direct sunlight by the amount of solar radiation. We investigated cumulative marketable yield over the same period.

Estimation of the amount of photosynthesis for strawberry by Kinect (Experiment 3)

As Kinect can estimate the amount of received light for each layer, we investigated whether this technology can be used to improve the evaluation of the amount of photosynthesis. 'Mouikko' strawberry plants were planted on September 18, 2017, in the same place (greenhouse-B) and with the same methods as in Experiment 1. The leaf area for each $10 \mathrm{~cm}$ layer was measured by destructive survey. Based on leaf stage, they were divided into young, middle-aged and old leaves. Young leaves were defined as leaves younger than fourth fully expanded leaf, old leaves were defined as those having a brown color, with all remaining leaves defined as middle-aged. Leaf area surveys were performed three times during the months of February and March, each survey on different sets of plants. Leaf nitrogen content was quantified with a $\mathrm{CN}$ analyzer (SUMIGRAPH NC-TR22; Sumika Chemical Analysis Service, Ltd., Osaka, Japan).

\section{RESULTS}

Measurement of plant height and amount of light received by leaf area and by layer in different cultivars and cultivation management using Kinect (Experiment 1)

Trends in plant height measured by Kinect and average temperature during the growing period of 'Mouikko' and 'Tochiotome' strawberry cultivars in greenhouse-A are shown in Fig. 2. In both cultivars, when the average temperature decreased (from December), plant height started to decrease, and the 'Tochiotome' cultivar was generally shorter than the 'Mouikko' cultivar.

Figure 3 shows the trends for leaf area receiving direct sunlight in 'Mouikko' cultivar measured by Kinect at different minimum night temperatures (greenhouse-A $5^{\circ} \mathrm{C}$, greenhouse- $\mathrm{B} 8^{\circ} \mathrm{C}$ ). From the results of the leaf area transition, differences in strawberry growth/height in these greenhouses occurred from December 2016 to March
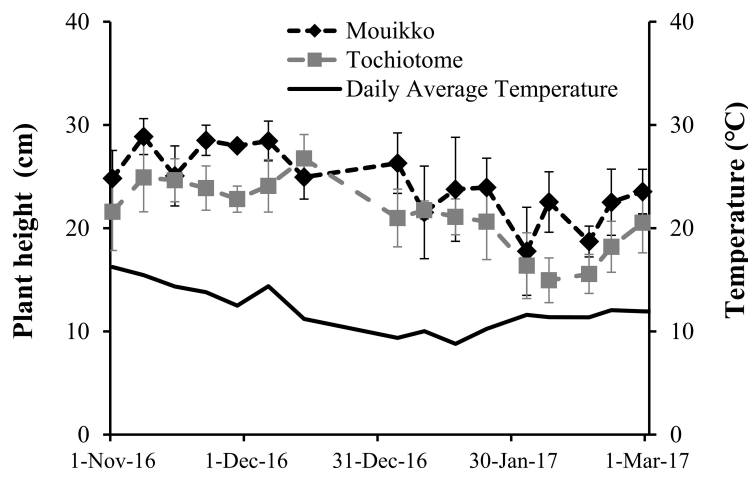

Fig. 2 Changes in plant height of two strawberry cultivars and average temperature of the cultivation environment. Plant heights were measured by Kinect. The data represent means \pm SEs of at least three independent experiments.
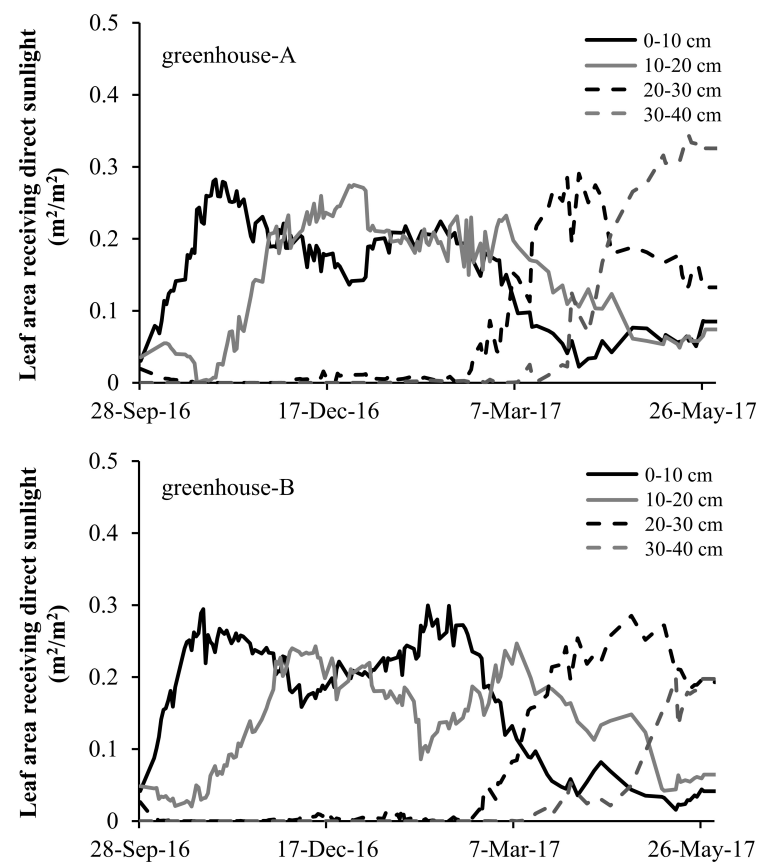

Fig. 3 Changes in leaf area receiving direct sunlight for each layer in strawberry plants in greenhouses with different night temperature management. Leaf area receiving direct sunlight indicates projected leaf area (per $\mathrm{m}^{2}$ ) measured with Kinect for each layer of the strawberry plant. For each cultivar, measurements were made for each layer at $0^{-}-10 \mathrm{~cm}, 10^{-}-20 \mathrm{~cm}, 20^{-}-30 \mathrm{~cm}$ and $30^{-40}$ $\mathrm{cm}$. Leaf area receiving direct sunlight for each cultivar was examined at three different spots and averaged. 


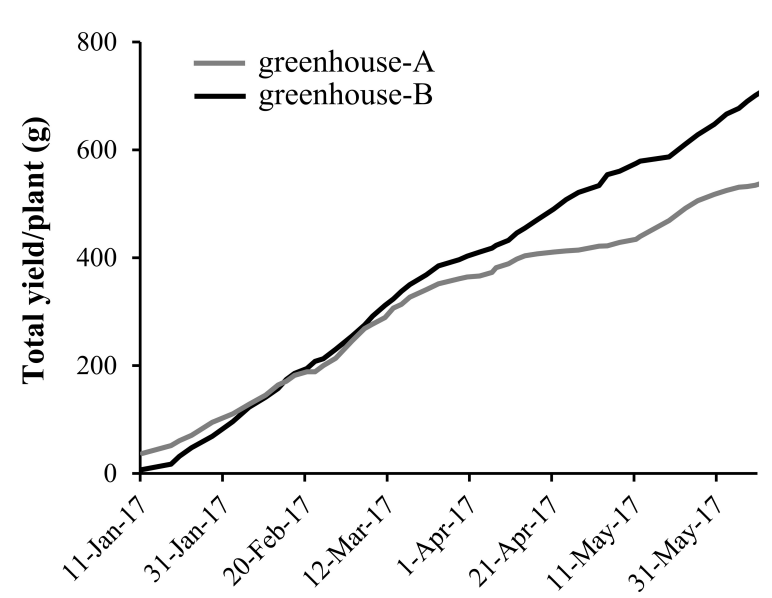

Fig. 4 Total yield of strawberries per plant in greenhouses with different minimum night temperatures (greenhouse-A $5^{\circ} \mathrm{C}$, greenhouse-B $8^{\circ} \mathrm{C}$ ).

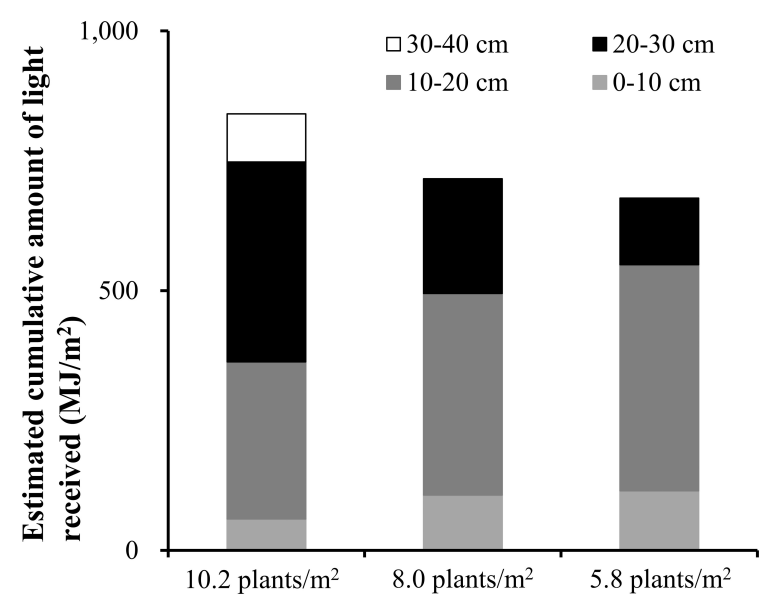

Fig. 5 Amount of light received by each layer of the strawberry community at different planting densities.

2017. In greenhouse-A, values of leaf area receiving direct sunlight to the $10^{-}-20 \mathrm{~cm}$ layer were low, and whole plant stature was small. The low minimum night temperature was thought to have affected growth in this time period. In addition, the increase in leaf area of the $20^{-} 30 \mathrm{~cm}$ and $30^{-}$ $40 \mathrm{~cm}$ layers after March was delayed in greenhouse-A compared with greenhouse-B. The total yield was higher in greenhouse-B than in the greenhouse-A starting from the middle of February, and the yield difference increased after spring (Fig. 4). The average yield of a strawberry plant at the end of June was $560.3 \mathrm{~g}$ in greenhouse-A and $748.4 \mathrm{~g}$ in greenhouse-B.

Relationship between the appearance of strawberry plants, the amount of received light using Kinect and yield at different planting densities (Experiment 2)

The strawberry plant appearance changed according to the planting density. At high planting density, plants grew taller, and the leaf area of the uppermost layer increased. As a result, the higher the planting density, the greater the cumulative amount of received light in the 20 $30 \mathrm{~cm}$ and $30^{-40} \mathrm{~cm}$ layers (Fig. 5). In addition, the total accumulated received light was highest at the highest den-

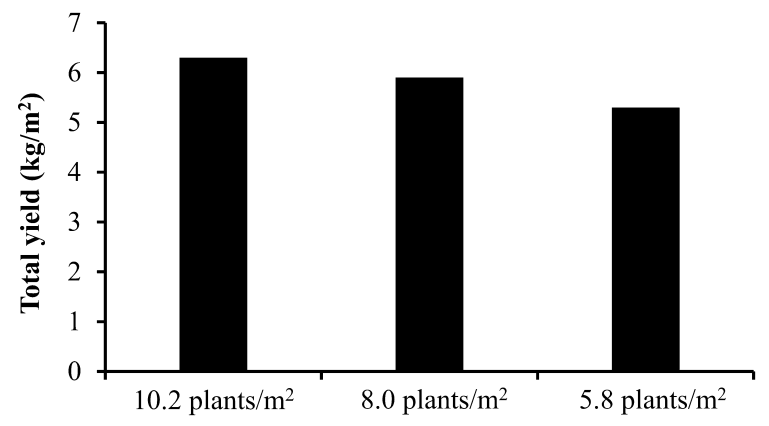

Fig. 6 Total yield of strawberry plants at different planting densities.

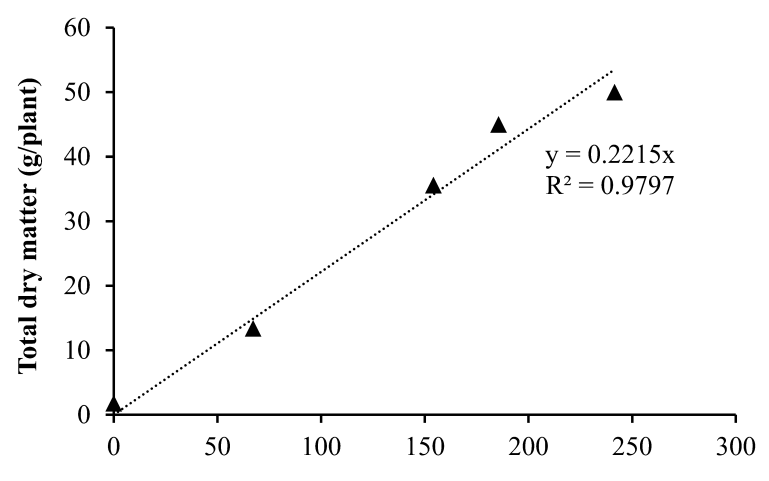

Estimated cumulative amount of light received $\left(\mathrm{MJ} / \mathrm{m}^{2}\right)$

Fig. 7 Correlation between total dry matter and light received by the strawberry plant community. Strawberry plants were disassembled and the amount of light received was assessed five times with Kinect during the cultivation period. Total dry matter was measured concurrently. Daily leaf area receiving direct sunlight was multiplied with daily solar radiation to estimate the cumulative amount of light received.

sity $\left(10.2\right.$ plants $\left./ \mathrm{m}^{2}\right)$. The total cumulative amount of light received by strawberries planted at 8.0 plants $/ \mathrm{m}^{2}$ was higher than that of strawberries planted at 5.8 plants $/ \mathrm{m}^{2}$, with large cumulative amounts received in the $20-30 \mathrm{~cm}$ layer at both densities. Similarly, yield data showed that yield decreased when strawberries were planted at lower densities (Fig. 6), mirroring results for cumulative amount of light received (Fig. 5). Total yield per square meter of strawberries at different planting densities was $6.3 \mathrm{~kg}$ at 10.2 plants $/ \mathrm{m}^{2}, 5.9 \mathrm{~kg}$ at 8.0 plants $/ \mathrm{m}^{2}$ and $5.3 \mathrm{~kg}$ at 5.8 plants $/ \mathrm{m}^{2}$.

Estimation of the amount of photosynthesis for strawberry by Kinect (Experiment 3)

The dry-matter weight of plants increases according to the amount of light received. We compared received light estimated by Kinect and dry weight. We found that dry-matter weight increased with the amount of received light (correlation coefficient $R^{2}=0.98$ ) (Fig. 7). Although Kinect was unable to measure the overlapping leaves, it was possible to estimate the amount of photosynthesis through dry-matter weight. The leaf age distribution per 10 $\mathrm{cm}$ leaf layer was investigated. From February to March 2018 the proportion of young leaves was high in the high layer $\left(20^{-30} \mathrm{~cm}\right)$ while the proportions of middle-aged 


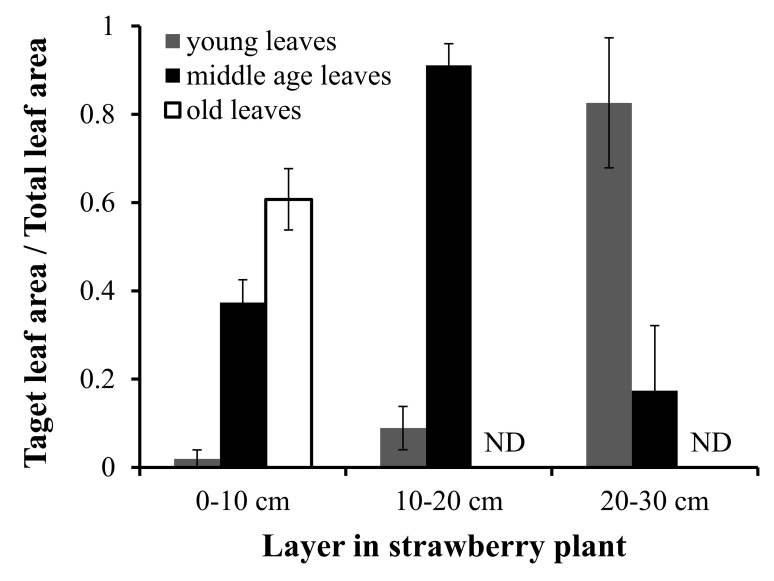

Fig. 8 Differences in the leaf age of strawberry plants in each layer. Leaf area each $10 \mathrm{~cm}$ layer was divided into young leaves, middle-aged leaves, and old leaves. The y-axis represents the proportional contribution of each leaf age to the total leaf area of the strawberry plant. ND: not detected. The data represent mean $\pm \mathrm{SE}$ of at least three independent experiments.

leaves and old leaves were high in the $10^{-}-20 \mathrm{~cm}$ and $0-10$ $\mathrm{cm}$ layers (Fig. 8). Leaf nitrogen (\% of dry mass) was similar in young leaves and middle-aged leaves but lower in old leaves (Table 1). The nitrogen content tended to be larger in leaves in the higher layers.

\section{DISCUSSION}

In the case of Dutch tomato cultivars, fruit yield is not correlated with harvest index but with total dry-matter (Higashide and Heuvelink, 2009). In the strawberry cultivars 'Benihoppe' and 'Toyonoka' as well, no difference in harvest index was observed between the cultivars, while 'Benihoppe' with higher fruit yield has higher dry-matter weight (Mochizuki et al., 2013). Short days and low temperatures induce dormancy in strawberries and they become dwarfed (Darrow and Waldo, 1933; Lee et al., 1968). To break the dormancy, temperatures close to $0^{\circ} \mathrm{C}$ and long-day photoperiods of over $12 \mathrm{~h}$ are required. Therefore, temperature control and lighting to extend day length (photoperiod) are necessary for promoting strawberry cultivation and avoiding dormancy. Such management is done either according to the calendar, or by the producer based on the appearance of the strawberry plants. For the strawberries at the lowest temperature of $5^{\circ} \mathrm{C}$ in Experiment 1, lower grass amounts led to a reduced yield in early spring. On the other hand, if turning off the lighting is delayed, strawberries tend to undergo vegetative growth, leading to a decrease in the number of flowers. To manage such factors accurately it is necessary to know the starting point and speed of change in the strawberry plant canopy. A depth sensor such as Kinect, which numerically indicates the spatial structure of leaves and their changes, can be used to solve problems in cultivation management. By obtaining data such as the plant height data shown in Fig. 2, it is possible to support the review of cultivation management and decision-making for environmental control settings.

In previous reports, it was demonstrated that plant height and leaf area of stratified leaves could be monitored using Kinect and the appearance of strawberry plants could be quantified (Takahashi et al., 2018). In this report, the amount of received light was estimated from the measured leaf area receiving direct sunlight and the amount of solar radiation, and a correlations between received light and yield and dry-matter weight was confirmed. On the basis of these data, we conclude that Kinect could be used not only for day-to-day cultivation management of strawberry plants but also for yield prediction and assessments of planting density based on the quantity of light received by the plant community.

Since dry-matter production in plants is directly related to the amount of photosynthesis, estimation of the amount of received light is important. To estimate the amount of light received by the plant community, several destructive surveys need to be conducted during the cultivation period to investigate LAI and calculate the canopy light extinction coefficient $(k)$. Although these data contribute greatly to good crop management, such as optimization of temperature control, they are rarely exploited because obtaining them is labor-intensive. While leaf area estimation by Kinect is very easy, overlapping leaf areas cannot be measured when Kinect is placed over the strawberry plants. However, these leaves do not receive direct sunlight, only scattered light. Also, in this study, the leaves in low layers were often old leaves with low nitrogen content, so they may be less important for growth. Because Kinect can measure the area of received light by leaf layer, if the photosynthetic activity of leaves varies among layers, estimating photosynthesis more accurately may be possible. Chen et al. (2014) analyzed the canopy in cucumber plants using ray tracing and measured photosynthetic ability at each leaf position to investigate what kind of community structure is desirable for improving overall canopy photosynthesis. In strawberries, the type of canopy structure most desirable for photosynthesis might be deduced from data collected by Kinect to maintain the proper equilibrium of vegetative and reproductive growth for high yield.

Table 1 Leaf nitrogen ( $\%$ of dry mass) in leaves of different ages and by layers.

\begin{tabular}{cccc}
\hline \multirow{2}{*}{ Leaf layer from the lower layer } & \multicolumn{3}{c}{ Leaf nitrogen (\% of dry mass) } \\
\cline { 2 - 4 } & Young leaves & Middle age leaves & Old leaves \\
\hline $0-10 \mathrm{~cm}$ & 3.0 & 2.9 & 2.5 \\
$10-20 \mathrm{~cm}$ & 3.2 & 3.0 & - $^{\mathrm{z}}$ \\
$20-30 \mathrm{~cm}$ & 3.2 & 2.9 & - \\
\hline
\end{tabular}

${ }^{\mathrm{z}}$ There were no old leaves in $10^{-}-20 \mathrm{~cm}$ and $20^{-}-30 \mathrm{~cm}$ layers. 


\section{TAKAHASHI ET AL.}

In this study, Kinect for Windows v1 was used, however, depth sensors capable of performing similar measurements are available from various other manufacturers. In addition, plant structures can also be acquired using SfMMVS (structure-from-motion and multiple-view stereo) and LiDAR (light detection and ranging) (Hosoi et al., 2011; Rose et al., 2015). Tools for acquiring plant growth information are becoming more diverse, and producers should select them in consideration of purpose and cost. In Miyagi Prefecture, information on cultivation environment is shared among producers and used in cultivation management. However, with environmental information alone, it is impossible to understand how each producer intends to control the environment. By combining daily environmental information and plant growth data, optimal cultivation management of strawberries becomes a possibility.

\section{ACKNOWLEDGEMENTS}

This work was supported by Ichimura Foundation for New Technology (Old name: The New Technology Development Foundation) and grants from the Project of the NARO Bio-oriented Technology Research Advancement Institution (research program on development of innovative technology). We thank Naoko Goto, Yukiko Honma, Manami Yusa and others for their great support in cultivating strawberries.

\section{REFERENCES}

Azzari, G., Goulden, M. L., Rusu, R. B. 2013. Rapid characterization of vegetation structure with a Microsoft Kinect sensor. Sensors 13: 2384-2398.

Chen, T.-W., Henke, M., de Visser, P. H. B., Buck-Sorlin, G., Wiechers, D., Kahlen, K., Stützel, H. 2014. What is the most prominent factor limiting photosynthesis in different layers of a greenhouse cucumber canopy? Ann. Bot. 114: 677688.

Darrow, G. M., Waldo, G. F. 1933. Photoperiodism as a cause of the rest period in strawberries. Science 77: 353-354.

Freedman, B., Shpunt, A., Machline, M., Arieli, Y. 2007. Depth mapping using projected patterns. U.S. Patent 20080240502 A1.

Hidaka, K., Dan, K., Miyoshi, Y., Imamura, H., Takayama, T., Kitano, M., Sameshima, K., Okimura, M. 2016. Twofold increase in strawberry productivity by integration of environmental control and movable beds in a large-scale greenhouse. Environ. Control Biol. 54: 79-92.

Higashide, T., Heuvelink, E. 2009. Physiological and morphological changes over the past 50 years in yield components in tomato. J. Am. Soc. Hortic. Sci. 134: 460-465.

Hosoi, F., Nakabayashi, K., Omasa, K. 2011. 3-D modeling of tomato canopies using a high-resolution portable scanning lidar for extracting structural information. Sensors 11: $2166^{-}$ 2174 .
Jiang, Y., Li, C., Paterson, A. H. 2016. High throughput phenotyping of cotton plant height using depth images under field conditions. Comput. Electron. Agric. 130: 57-68.

Kaize, Y., Choi, J.-M., Kang, T.-H. 2012. Grass height and yield estimation using a three-dimensional laser scanner. Environ. Control Biol. 50: 41-51.

Khoshelham, K., Elberink, S. O. 2012. Accuracy and resolution of Kinect depth data for indoor mapping applications. Sensors 12: $1437-1454$.

Kim, J. H., Lee, J. W., Ahn, T. I., Shin, J. H., Park, K. S., Son, J. E. 2016. Sweet pepper (Capsicum annuum L.) canopy photosynthesis modeling using 3D plant architecture and light ray-tracing. Front. Plant Sci. 7: 1321.

Kurosaki, H., Hamamoto, H., Iwasaki, Y., Umeda, H. 2016 a. Environment controlling system for plant cultivation. Japan Patent. 2016-52293. 2016-6-14.

Kurosaki, H., Hamamoto, H., Iwasaki, Y., Umeda, H. 2016 b. Plant community structure analysis system. Japan Patent. 201653903. 2016-4-14.

Lee, B. Y., Takahashi, K., Sugiyama, T. 1968. Studies on dormancy in strawberry plants. I . (in Japanese with English abstract) J. Jpn. Soc. Hortic. Sci. 37: 129-134.

Li, D., Xu, L., Tan, C., Goodman, E., Fu, D., Xin, L. $2015 . \quad$ Digitization and visualization of greenhouse tomato plants in indoor environments. Sensors 15: 4019-4051.

Lieten, F. 1997. Effect of $\mathrm{CO}_{2}$ enrichment on greenhouse grown strawberry. Acta Hortic. 439: 583-586.

Mochizuki, Y., Iwasaki, Y., Funayama, M., Ninomiya, S., Fuke, M., Nwe, Y.Y., Yamada, M., Ogiwara, I. 2013. Analysis of a high-yielding strawberry (Fragaria $\times$ ananassa Duch.) cultivar 'Benihoppe' with focus on dry matter production and leaf photosynthetic rate. (in Japanese with English abstract) J. Jpn Soc. Hortic. Sci. 82: 22-29.

Monteith, J. L. 1965. Light distribution and photosynthesis in field crops. Ann. Bot. 29: 17-37.

Paulus, S., Behmann, J., Mahlein, A.-K., Plümer, L., Kuhlmann, H. 2014. Low-cost 3D systems: suitable tools for plant phenotyping. Sensors 14: 3001-3018.

Rose, J. C., Paulus, S., Kuhlmann, H. 2015. Accuracy analysis of a multi-view stereo approach for phenotyping of tomato plants at the organ level. Sensors 15: 9651-9665.

Takahashi, M., Umeda, H., Iwasaki, Y., Koike, O., Takayama, S., Kano, H., Honma, Y., Goto, N., Sugeno, W., Yusa, M. 2018. Development of three-dimensional shape measurement technology for strawberries. Acta Hortic. 1227: 387-392.

Umeda, H., Mochizuki, Y., Saito, T., Higashide, T., Iwasaki, Y. 2018. Diagnosing method for plant growth using a 3D depth sensor. Acta Hortic. 1227: 631-636.

Vince-Prue, D., Guttridge, C. G. 1973. Floral initiation in strawberry: Spectral evidence for the regulation of flowering by long-day inhibition. Planta 110: 165-172.

Wada, Y., Soeno, T., Inaba, Y. 2010. Effects of light and temperature on photosynthetic enhancement by high $\mathrm{CO}_{2}$ concentration of strawberry cultivar Tochiotome leaves under forcing or half-forcing culture. (in Japanese with English abstract) Jpn. J. Crop Sci. 79: 192-197.

Zhang, Y., Teng, P., Shimizu, Y., Hosoi, F., Omasa, K. 2016. Estimating 3D leaf and stem shape of nursery paprika plants by a novel multi-camera photography system. Sensors 16: 874 . 